\title{
RAB27A, RAB27B and VPS36 are downregulated in advanced prostate cancer and show functional relevance in prostate cancer cells
}

\author{
THOMAS STEFAN WORST ${ }^{1 *}$, YANNIC MEYER ${ }^{1 *}$, MARIA GOTTSCHALT $^{2}$, CLEO-ARON WEIS $^{2}$, \\ JOST VON HARDENBERG ${ }^{1}$, CHRISTINE FRANK ${ }^{1}$, ANNETTE STEIDLER ${ }^{1}$, \\ MAURICE STEPHAN MICHEL ${ }^{1}$ and PHILIPP ERBEN ${ }^{1}$ \\ ${ }^{1}$ Department of Urology and ${ }^{2}$ Institute of Pathology, Mannheim Medical Center, \\ University of Heidelberg, D-68167 Mannheim, Germany
}

Received September 30, 2016; Accepted December 5, 2016

DOI: $10.3892 /$ ijo.2017.3872

\begin{abstract}
Paracrine and long-range signaling via extracellular vesicles, such as exosomes and microvesicles, is deemed crucial for tumorigenesis, invasion and spread of solid tumors. The ESCRT machinery (endosomal sorting complexes required for transport) and Rab-proteins act as key players in vesicular trafficking and secretion. Yet, their role in prostate cancer (PCa) is unknown. Therefore, this study aimed to elucidate the relevance of these components in $\mathrm{PCa}$. In silico reanalysis of genes with known involvement in vesicular trafficking and secretion in an existing microarray dataset revealed low expression of RAB27A, RAB27B and VPS36 to be predictive for reduced $\mathrm{BCR}$-free survival in patients with localized PCa ( $\mathrm{p}=0.033,0.025$ and 0.005$)$. In the same microarray dataset underexpression of RAB27A, RAB27B and VPS36 was seen in distant metastases $(p<0.001 ; p=0.003$; $\mathrm{p}<0.001)$. This was consistent in two further microarray datasets. qRT-PCR-validation in two independent cohorts of PCa specimens $(n=90)$ showed low expression of VPS36 in PCa tissue $(\mathrm{p}=0.023)$, especially in castration-resistant tumors $(\mathrm{p}=0.002)$. In all five datasets there were significant correlations between the expression of at least two of the candidates.
\end{abstract}

Correspondence to: Dr Thomas Stefan Worst, Department of Urology, Mannheim Medical Center, University of Heidelberg, Theodor-Kutzer-Ufer 1-3, D-68167 Mannheim, Germany

E-mail: thomas.worst@medma.uni-heidelberg.de

*Contributed equally

Abbreviations: AD, androgen dependent; AR, androgen receptor; $\mathrm{BCR}$, biochemical recurrence; CR, castration-resistant; FFPE, formalin-fixed paraffin-embedded tissue; PCa, prostate cancer; PSA, prostate-specific antigen; PSMA, prostate-specific membrane antigen; TUR-P, transurethral resection of the prostate

Key words: prostate cancer, extracellular particles, secretion, vesicular trafficking, extracellular vesicles, VPS36, RAB27A, RAB27B, hormone resistance, biomarker, progression
Upon knockdown of VPS36 an increase of RAB27A and RAB27B expression, but not vice versa, was observed in both prostate and breast cancer cells (PC3, MDA-MB-231). In PC3 cell knockdown of RAB27B and VPS36 dramatically reduced colony formation $(-52.2 \%, \mathrm{p}<0.001 ;-71.1 \%, \mathrm{p}<0.001)$ and, controversial to reports in other tumor entities, increased the release of extracellular particles $(+25.3 \%, \mathrm{p}=0.014 ;+45.6 \%$, $\mathrm{p}<0.001)$. Taken together RAB27A, RAB27B and VPS36 are frequently underexpressed in advanced $\mathrm{PCa}$ and are inversely correlated with PCa outcome. There seems to be a close relationship in the expression of RAB27A, RAB27B and VPS36, with RAB27A and RAB27B being dependent on VPS36. Changes in colony formation and particle release upon RNAi indicate an involvement in paracrine cell-cell communication.

\section{Introduction}

Prostate cancer $(\mathrm{PCa})$ is the most common solid cancer entity among men in industrialized countries (1). Annually more than 250,000 men die from metastasized PCa worldwide. However, many aspects in PCa development and progression are still unknown.

In many different cancer entities signaling via extracellular particles has impact on different tumor-related processes $(2,3)$. Especially extracellular vesicles are in the focus of current research. They play a role in modulation of tumor microenvironment (4), neo-angiogenesis (5), metastatic niche formation (6) and systemic inflammation (7). PCa extracellular vesicles are involved in crosstalk between tumor cells and the surrounding stroma $(8,9)$.

Exosomes are the best-studied subpopulation of extracellular vesicles. They have a typical size of 30-100 $\mathrm{nm}$ and, unlike the larger microvesicles which directly originate from the plasma membrane, are generated from the membranes of endosomes. These endosomes are termed as multi-vesicularbodies (MVB). Exosome generation is mainly mediated by the components of the ESCRT machinery (endosomal sorting complexes required for transport), with tetraspaninrich microdomains and lipids like sphingosin-1-phosphate also being involved in these processes (10-12). MVBs release 
exosomes into the extracellular space by fusion with the plasma membrane (12). Based on current knowledge, fusion with the plasma membrane is mainly mediated by the GTPases RAB27A and RAB27B (13). Further proteins such as Plectin and Rab11 are also involved in this process (12). Extracellular vesicles are rich in proteins involved in membrane transportation and membrane fusion (GTPases, annexins, flotillins), tetraspanins like CD9, CD63 and CD81, heat shock proteins HSP70 and HSP90 and proteins involved in MVB formation such as ALIX and TSG101 (14,15). Compared to microvesicles, the composition of exosomes is more stringently controlled by specific processes (16-18).

Many studies deal with the function of extracellular vesicles and their potential use as biomarkers. However, not much is known about the role of genes involved in vesicular trafficking and secretion, in cancer. Therefore, it was the aim of this study to elucidate their relevance in PCa. Their expression was re-analyzed in existing microarray data with regard to PCa patient outcome prediction. qRT-PCR profiling of $\mathrm{PCa}$ tissue samples at various stages served as validation. In vitro studies were done to functionally examine the impact of the genes associated with patient outcome on proliferation, colony formation and release of extracellular particles.

\section{Materials and methods}

Candidate list generation and in silico analyses. Based on recent literature a list of genes with known functions in vesicular trafficking and secretion, like the ESCRT components TSG101, MVB12, VPS36 and PDCD6IP (ALIX), and of typical extracellular vesicle markers (e.g., flotillins and the tetraspanins CD9, CD63 and CD81) was assembled. Furthermore, genes typically associated with $\mathrm{PCa}$, such as KLK3 (PSA) or PTEN were added. The full list of genes is given in Table I. RNA expression data and clinical and pathological parameters of a PCa dataset (19), comprising of 131 primary (mean age, $58.03 \pm 6.99$ years; mean PSA, $8.48 \pm 12.28 \mathrm{ng} / \mathrm{ml}$; T2, 85; T3, 40; T4, 6) and 19 metastatic tumor samples (mean age, 60.51 7.38 years; mean PSA, $72.99 \pm 135.59 \mathrm{ng} / \mathrm{ml}$ ) were derived from cBioPortal (20). Gene expression in tumor samples is compared to healthy controls and adjacent tumor-free tissue.

The expression $\mathrm{z}$-scores in patients with localized PCa, obtained from the original data, were used to define expression cut-off values (high vs. low expression) for the event of biochemical recurrence (BCR). Calculations were done using the partition test in SAS JMP 11 (SAS Institute, Cary, NC, USA). These cut-off values were applied to the cohort and correlated with BCR-free survival using log-rank test. Only candidates with $>20$ patients in the high and low expression groups were followed-up. BCR-free survival was displayed using Kaplan-Meier graphs. In candidates reaching significance for prediction of BCR, expression values were stratified according to T-stage and Gleason grade. Correlation with clinical and pathological parameters was additionally done using two further microarray datasets (Tomlins et al and $\mathrm{Yu}$ et al) $(21,22)$. In all three datasets correlations between the expression of the different candidate genes were done using Spearman correlation.
Cohorts and patient samples. A cDNA array (Origene, Rockville, MD, USA) consisting of 40 localized PCa and 8 benign control samples was used as a first step to independently re-test the expression of RAB27A, RAB27B and VPS36. Patient characteristics of this cohort are shown in Table II. Expression of all three candidates was correlated with T-stage and Gleason grade.

In a second step a cohort of 41 patients who underwent transurethral resection of PCa for palliation in the Department of Urology of the Mannheim Medical Center between May 2005 and September 2015 was retrospectively analyzed. Nine patients were treated twice with transurethral resection, resulting in a total of 50 FFPE tumor samples. FFPE prostate tissue specimen of ten patients who underwent transurethral resection due to benign prostatic hyperplasia (BPH), histologically negative for $\mathrm{PCa}$, served as controls. Patient data of this cohort is given in Table III. All experiments were in accordance with the institutional ethics review board (Medical Ethics Committee II of the Medical Faculty Mannheim, ethics approval 2013-845R-MA). Expression data were correlated with tumor stage and Gleason grade in both datasets. In tumor samples obtained from transurethral resection further correlations with castration resistance were done.

RNA-extraction and cDNA-synthesis. Tumor-bearing and tumor-free FFPE prostate tissue specimen of patients from our institution were sectioned and stained with hematoxylin and eosin and reviewed microscopically. Subsequent unstained $10-\mu \mathrm{m}$ sections were placed on glass slides. Tissue sections of control patients and those of PCa patients bearing $\geq 80 \%$ of tumor tissue were used completely. On sections containing $<80 \%$ of tumor, non-tumorous areas were scratched off prior to RNA extraction using a sterile scalpel. Sections were deparaffinized three times in $2 \mathrm{ml}$ of Neo Clear (Merck Millipore, Billerica, MA, USA). The deparaffinized tissue was then scraped off the glass slides into a reaction tube containing $150 \mu \mathrm{l}$ of lysis buffer. RNA extraction was conducted with the XTRACT FFPE kit (Stratifyer, Cologne, Germany) as suggested by the manufacturer $(23,24)$. In brief the tubes were incubated $30 \mathrm{~min}$ at $80^{\circ} \mathrm{C}$ with shaking. After cooling to $65^{\circ} \mathrm{C}$ $50 \mu \mathrm{l}$ of Proteinase K (Promega, Fitchburg, WI, USA) were added and incubated for $30 \mathrm{~min}$ with shaking. Subsequently $800 \mu \mathrm{l}$ of MagiX-RNA buffer and $40 \mu \mathrm{l}$ of MagiX-RNA ferromagnetic beads were added and incubated $15 \mathrm{~min}$ at room temperature with shaking. The tubes were placed on a magnetic rack and the supernatant was removed. Three washing steps were subsequently conducted, after each washing, supernatant was removed with the tubes on the magnetic rack. The RNA was eluted by adding $100 \mu$ l of elution buffer which was incubated for $15 \mathrm{~min}$ at $70^{\circ} \mathrm{C}$. With the tube on the magnetic rack the supernatant, containing the RNA, was transferred to a new reaction tube and either used immediately or stored at $-80^{\circ} \mathrm{C}$. RNA-concentration was determined spectrophotometrically using the NanoDrop 1000 (Thermo Fisher Scientific, Waltham, MA, USA).

cDNA synthesis was performed using the SuperScript III reverse transcription kit (Thermo Fisher Scientific) with sequence specific primers. In brief $2.5 \mu \mathrm{l}$ of forward primers of RAB27A, RAB27B, VPS36, androgen receptor (AR) or the house keeping gene calmodulin 2 (CALM2), $1 \mu 1$ of 
Table I. A list of genes identified from the literature with known function in exosome biogenesis and secretion and known PCa biomarkers was assembled for further in silico analyses. ${ }^{a}$

\begin{tabular}{|c|c|c|}
\hline Group & Gene symbol & Gene name \\
\hline \multirow[t]{7}{*}{ Known PCa markers } & AMACR & $\alpha$-methylacyl-CoA racemase \\
\hline & $\mathbf{A R}$ & Androgen receptor \\
\hline & EZH2 & Enhancer of zeste 2 polycomb repressive complex 2 subunit \\
\hline & FOLH1 (PSMA) & Folate hydroxylase 1 (prostate specific membrane antigen) \\
\hline & KLK3 (PSA) & Kallikrein 3 (prostate specific antigen) \\
\hline & PCA3 & Prostate cancer antigen 3 \\
\hline & PTEN & Phosphatase and tensin homolog \\
\hline \multirow[t]{3}{*}{ ESCRT-0 } & STAM1 & Signal transducing adaptor molecule 1 \\
\hline & STAM2 & Signal transducing adaptor molecule 2 \\
\hline & VPS27 & Vacuolar protein sorting 27 homolog \\
\hline \multirow[t]{6}{*}{ ESCRT-I } & MVB12 & Multivesicular body subunit 12 \\
\hline & PDCD6IP & Programmed cell death 6 interacting protein \\
\hline & TSG101 & Tumor susceptibility gene 101 \\
\hline & UBAP1 & Ubiquitin associated protein 1 \\
\hline & VPS28 & VPS28, ESCRT-I subunit \\
\hline & VPS37 & VPS37, ESCRT-I subunit \\
\hline \multirow[t]{3}{*}{ ESCR-II } & SNF8 (EAP30) & SNF8, ESCRT-II complex subunit \\
\hline & VPS25 (EAP20) & Vacuolar protein sorting 25 homolog \\
\hline & VPS36 (EAP45) & Vacuolar protein sorting 36 homolog \\
\hline \multirow[t]{4}{*}{ ESCRT-III } & CHMP6 & Charged multivesicular body protein 6 \\
\hline & IST1 & IST1, ESCRT-III associated factor \\
\hline & VPS4A & Vacuolar protein sorting 4 homolog A \\
\hline & VTA1 (LIP5) & Vesicle trafficking 1 \\
\hline \multirow[t]{7}{*}{ Rab-kinases } & RAB5a & RAB5A, member RAS oncogene family \\
\hline & Rab11 & RAB 11, member RAS oncogene family \\
\hline & RAB27A & RAB27A, member RAS oncogene family \\
\hline & RAB27B & RAB27B, member RAS oncogene family \\
\hline & Rab35 & RAB35, member RAS oncogene family \\
\hline & RAB36 & RAB36, member RAS oncogene family \\
\hline & TBC1D10A (EPI64) & TBC1 domain family member $10 \mathrm{~A}$ \\
\hline \multirow[t]{14}{*}{ Exosome-associated genes } & CD9 & CD9 molecule \\
\hline & CD63 & CD63 molecule \\
\hline & CD81 & CD81 molecule \\
\hline & СНMP4C & Charged multivesicular body protein $4 \mathrm{C}$ \\
\hline & DCT (TYRP2) & Dopachrome tautomerase \\
\hline & EPCAM & Epithelial cell adhesion molecule \\
\hline & FLOT1 & Flotillin 1 \\
\hline & FLOT2 & Flotillin 2 \\
\hline & HSP4A & Heat shock protein family A (Hsp70) member 4 \\
\hline & HSP90AA1 & Heat shock protein $90 \alpha$ family class A member 1 \\
\hline & MMP2 & Matrix metallopeptidase 2 \\
\hline & MMP9 & Matrix metallopeptidase 9 \\
\hline & MMP14 & Matrix metallopeptidase 14 \\
\hline & STEAP3 & STEAP3 metalloreductase \\
\hline
\end{tabular}

${ }^{\mathrm{a}}$ Genes printed in non-bold letters were omitted from further analyses as they were not available in the analyzed dataset. 
Table II. Patient characteristics in the Origene cDNA array.

\begin{tabular}{lcc}
\hline Patients & Localized PCa $(\mathrm{n}=40)$ & BPH $(\mathrm{n}=8)$ \\
\hline Mean age (SD) & $62.75 \pm 8.15$ & $64.15 \pm 10.9$ \\
T1 & - & \\
T2 & 22 & \\
T3 & 12 & \\
T4 & - & \\
Not specified & 6 \\
Gleason 5 & 2 \\
Gleason 6 & 8 \\
Gleason 7a & 14 \\
Gleason 7b & 8 \\
Gleason 8 & 3 \\
Gleason 9 & 4 \\
Not specified & 1 \\
\hline
\end{tabular}

$10 \mathrm{mM}$ dNTP Mix and $3.5 \mu \mathrm{l}$ of nuclease-free $\mathrm{H}_{2} \mathrm{O}$ were added to $5 \mu 1$ of RNA template. This mixture was incubated for $10 \mathrm{~min}$ at $65^{\circ} \mathrm{C}$ and was subsequently cooled on ice. For cDNA synthesis $4 \mu 1$ of First Strand synthesis buffer, $1 \mu 1$ of $0.1 \mathrm{M}$ DDT, $1 \mu \mathrm{l}$ of RNAseOut (Thermo Fisher Scientific) and $2 \mu \mathrm{l}$ of SuperSript III reverse transcriptase were added and incubated for $120 \mathrm{~min}$ at $70^{\circ} \mathrm{C}$. cDNA was immediately used for qRT-PCR or stored at $-20^{\circ} \mathrm{C}$.

qRT-PCR analyses in patient samples. The expression of RAB27A, RAB27B and VPS36 was determined in all samples of the cDNA array in relation to the housekeeping gene CALM2. For all assays intron spanning primer pairs were designed using Primer-BLAST, based on the primer3 algorithm (25).

In brief, $10 \mu \mathrm{l}$ of TaqMan Fast Universal PCR Mastermix (Life Technologies, Darmstadt, Germany), $0.75 \mu 1$ of forward and reverse primer, each $(300 \mathrm{nM}), 0.5 \mu 1$ of PCR probe $(200 \mathrm{nM})$ (both MWG Eurofins, Ebersberg, Germany) and $6 \mu$ l of nuclease-free $\mathrm{H}_{2} \mathrm{O}$ were added to $2 \mu \mathrm{l}$ of cDNA template. Subsequently 50 cycles of PCR amplification with $3 \mathrm{sec}$ of $95^{\circ} \mathrm{C}$ and $30 \mathrm{sec}$ of $60^{\circ} \mathrm{C}$ were conducted in a StepOnePlus ${ }^{\mathrm{TM}}$ System (Thermo Fisher Scientific). Relative candidate gene expression normalized to the expression of CALM2 was calculated in reference to the average expression in non-tumorous samples using the $2^{-\triangle \Delta C T}$-method (26). Expression of each gene was correlated with clinical data. Correlations between the expression of different genes were done using Spearman correlation.

Cell lines, siRNA knockdown and qRT-PCR of in vitro samples. Human PC3 metastatic PCa cells and MDA-MB-231 breast cancer cells, which is a well-studied model in case of extracellular vesicle release, were obtained from ATCC (Wesel, Germany) and grown under standard conditions either in DMEM (PC3) or RPMI (MDA-MB-231) (each from Life Technologies) supplemented with 10\% FCS (Sigma-Aldrich, St. Louis, MO, USA) and $2 \mathrm{nM}$ glutamine (Life Technologies).
Table III. Patient characteristics in the TUR cohort.

\begin{tabular}{|c|c|c|}
\hline $\begin{array}{l}\text { Patients } \\
\text { Samples }\end{array}$ & $\begin{array}{l}\mathrm{PCa}(\mathrm{n}=41) \\
\mathrm{PCa}(\mathrm{n}=50)\end{array}$ & $\begin{array}{l}\text { BPH }(n=10) \\
\text { BPH }(n=10)\end{array}$ \\
\hline Mean age (SD) & $75.48 \pm 6.86$ & $66.9 \pm 13.56$ \\
\hline Hormone-sensitive & $74.43 \pm 6.13$ & \\
\hline Castration-resistant & $75.89 \pm 7.15$ & \\
\hline Hormone-sensitive & 14 & \\
\hline Gleason 5: & 2 & \\
\hline Gleason 6 & 3 & \\
\hline Gleason 7 & 4 & \\
\hline Gleason 8 & 4 & \\
\hline Gleason 9 & 1 & \\
\hline Castration-resistant & 36 & \\
\hline
\end{tabular}

${ }^{a}$ Age and tumor characteristics are given with regard to the number of samples.

Cell lines were transfected with siGenome pooled and individual siRNAs against RAB27A, RAB27B and VPS36 at a concentration of $30 \mathrm{nmol}$ using Dharmafect I transfection reagent (all from Dharmacon, Lafayette, USA). Dharmacon non-targeting siRNA served as negative control. Transfection was conducted as recommended by the manufacturer with minor modifications. While cells were detached, harvested, spun down and diluted to the desired concentration, siRNA and Dharmafect I were separately incubated in pure RPMI (Life Technologies) for $10 \mathrm{~min}$ at room temperature and where then mixed 1:1 for subsequent $30 \mathrm{~min}$ incubation at room temperature. Hereafter cell suspension was added to the transfection mix $3: 1$ and incubated at $37^{\circ} \mathrm{C}$. The supernatant was replaced with fresh medium after $24 \mathrm{~h}$.

RNA-extraction was performed after further $48 \mathrm{~h}$ using RNeasy Mini kit (Qiagen, Hilden, Germany) according to the recommendations of the manufacturer. For cNDA-synthesis $40 \mu 1$ of diluted RNA were mixed with $4 \mu 1$ of $5 \mathrm{mg} / \mathrm{ml}$ pdN6 random primers, $4 \mu 1$ of $10 \mathrm{mM}$ dNTP Mix, $16 \mu \mathrm{l}$ of 5X M-MLV buffer, $8 \mu \mathrm{l}$ of $0.1 \mathrm{M}$ RNase inhibitor, $4 \mu \mathrm{l}$ of $0.1 \mathrm{M}$ DTT and $4 \mu 1$ of M-MLV reverse transcriptase (all from Roche Diagnostics). After an incubation for $2 \mathrm{~h}$ at $37^{\circ} \mathrm{C}$ and a deactivation step of $5 \mathrm{~min}$ at $65^{\circ} \mathrm{C}$, cDNA was directly used for qRT-PCR or stored at $-20^{\circ} \mathrm{C}$. qRT-PCR was performed and analyzed analogously to patient samples.

qRT-PCR was conducted to validate knockdown efficiency and to monitor the impact of the knockdown of one candidated gene on the other two. PCR experiments and functional assays were conducted in three biological replicates each.

Proliferation assay. PC3 cells were seeded and transfected following the protocol described above in 96-well plates with a total volume of $100 \mu \mathrm{l} / \mathrm{well}$. After $24 \mathrm{~h}$ the supernatant was replaced by $100 \mu \mathrm{l}$ of fresh growth medium. After further 24, 48 and $72 \mathrm{~h}$ of incubation, $10 \mu \mathrm{l}$ of MTT-reagent (Promega) was added per well and incubated for $3 \mathrm{~h}$ at $37^{\circ} \mathrm{C}$. Absorption measurement at $570 \mathrm{~nm}$ was performed using an Infinite M1000 Pro plate reader (Tecan, Männerdorf, Switzerland). 
Scratch assay. Using the same transfection protocol, PC3 cells were seeded in 24-well plates with a volume of $1 \mathrm{ml}$ per well. The medium was changed $24 \mathrm{~h}$ after transfection. Again $24 \mathrm{~h}$ later a defined scratch was introduced in the center of the well, using a sterile $200 \mu$ l pipette tip. The medium was changed again. At this point of time and after further 24, 48 and $72 \mathrm{~h}$ the scratch was photographed at a $\times 20$ magnification. The calculation of the cell-free space in the scratch area was performed with the open source software tscratch (ETH Zürich, Switzerland) (27). The open area $24 \mathrm{~h}$ after scratch was compared to the initial scratch size.

Colony formation assay. In total, 500 PC3 cells were seeded and transfected per well in 6-well plates. Medium was changed after $24 \mathrm{~h}$. After 14 days of cultivation, the supernatant was removed and the cells were stained using $0.05 \%$ crystal violet for $15 \mathrm{~min}$. Wells were photographed at $\times 20$ and the number of colonies was counted.

Nanoparticle tracking analysis of supernatant of transfected and inhibitor-treated cells. PC3 cells were seeded and transfected in 24-well plates as described above. Forty-eight hours after transfection the supernatant was removed and the cells were washed with sterile PBS two times. Afterwards cells were again incubated for $48 \mathrm{~h}$ in serum-free RPMI medium. Subsequently the supernatant was recovered and sequentially centrifuged at 300,2,000 and 12,000 g to remove cellular debris, larger particles and microvesicles. Each sample of cleared supernatant was measured five times for $45 \mathrm{sec}$ using nanoparticle tracking analysis (NTA) on an LM10 (Malvern Instruments, Malvern, UK) at dilutions between 1:20 and 1:50. Particle concentration and size were determined. The same was done for the supernatant of PC 3 cells treated with the sphingomyelinase inhibitor GW4869, known to block exosome release in vitro. For GW4869 a concentration of $5 \mathrm{ng} / \mu 1$ in $1.7 \%$ DMSO was chosen. The same concentration of DMSO without inhibitor served as control condition.

Statistics. Statistical calculations and graph design were performed using Prism 6 (GraphPad Software, Inc., La Jolla, CA, USA) or JMP 11 (SAS Institute GmbH, Heidelberg, Germany). Testing for normality showed non-normal data distribution in all tested datasets thus non-parametric tests were used. Calculation of inter-group gene expression changes, for both in silico cohorts and patient samples analyzed with qRT-PCR, were performed using Mann-Whitney test. Correlation of candidate gene expression was done using Spearman correlation. Differences in BCR were calculated using log-rank test. For in vitro assays parametric t-test was used. P-values $\leq 0.05$ were considered statistically significant.

\section{Results}

Several candidate genes are associated with BCR in localized $P C a$ in silico. Thirty-seven genes either involved in vesicular trafficking and secretion or typically present on extracellular vesicles were identified from recent literature. These and five genes associated with PCa were tested in the microarray dataset of localized PCa by Taylor et al (19) for their prediction of BCR. Gene expression cut-off levels, defined by partition test, divided the dataset into two groups of patients for each candidate, one group with candidate gene high expression and the other with candidate gene low expression. Table IV summarizes cut-off values, group sizes, number of BCR-events and p-values of log-rank test for BCR. For 22 genes a significant correlation between gene expression and BCR was seen. Yet, for many genes partition test had resulted in very imbalanced group sizes. With a minimum group size requirement set to 20 patients, six genes remained. KaplanMeier graphs with BCR-free survival as outcome parameter for these genes are displayed in Fig. 1. Beside genes known to be associated with PCa outcome, such as EZH2 and PTEN, there were also the two RABs RAB27A and RAB27B and the ESCRT-II component VPS36 associated with BCR. In case of the latter three candidates a lower expression was predictive for a worse outcome.

$R A B 27 A, R A B 27 B$ and VPS36 are overexpressed in metastatic $P C a$ in silico. The dataset by Taylor et al (19) was used to stratify gene expression of RAB27A, RAB27B and VPS36 for tumor stage. Both for RAB27A and RAB27B a significantly decreased expression in distant metastatic lesions (RAB27A: $\mathrm{p}<0.001$; RAB27B: $\mathrm{p}<0.001$ ) but not in primary tumors and lymph node metastases (Fig. 2A and B) was seen.

The expression of VPS36 was significantly reduced in locally advanced PCa ( $\mathrm{p}=0.041)$, as well as in lymph node $(p=0.003)$ and distant metastases $(p<0.001)$ (Fig. 2 C). These findings were re-assessed in two other publicly available microarray datasets. In the Tomlins et al dataset (21) the three candidate genes were significantly reduced in tumors with Gleason score $\geq 7 b$ (RAB27A, $p=0.007$; RAB27B, $p=0.003$; VPS36, $\mathrm{p}=0.001)$ and metastatic lesions (RAB27A, $\mathrm{p}<0.001$; RAB27B, p<0.001; VPS36, p<0.001) (Fig. 2D-F). In the Yu et al dataset (22) all three candidates were underexpressed in metastases (RAB27A, $p=0.0389$; RAB27B, $p<0.001$; VPS36, $\mathrm{p}=0.001)$. RAB27B was also higher expressed in stage 2 tumors ( $\mathrm{p}=0.014)$ (Fig. 2G-H).

Expression of candidate genes correlates among each other in silico. Analysis of microarray datasets furthermore revealed the expression of RAB27A, RAB27B and VPS36 to be positively correlated with each other. A low expression of RAB27A was associated with a low expression of RAB27B in all three datasets. In the Taylor et al dataset (19) expression of both genes was also positively correlated with the expression of VPS36. This could partly be confirmed in the other two datasets. Bivariate correlation plots are shown in Fig. 3A-C for the Taylor et al dataset (19) exemplarily. For the two other analyzed datasets correlation coefficients and p-values are shown as interaction graphs in Fig. 3D and E.

VPS36 expression is decreased in advanced primary PCa. To validate these findings in independent patient samples with a different technique, two cohorts of PCa patients and benign prostatic tissue controls were analyzed using qRT-PCR. In the cDNA array consisting of 40 patients with localized PCa and 8 patients with $\mathrm{BPH}$ no altered expression of all three candidates, compared to benign controls, was seen when stratifying for tumor stage and Gleason score (data not shown). Consistent with the in silico analyses, RAB27A and RAB27 
Table IV. Cut-off values, group sizes, number of BCR-events and p-values of the log-rank test for time to BCR for 37 genes tested in the Taylor et al dataset (19) are displayed. ${ }^{a}$

\begin{tabular}{|c|c|c|c|c|}
\hline Gene & $\begin{array}{l}\text { Cut-off } \\
\text { (z-score) }\end{array}$ & $\begin{array}{l}\text { High expression } \\
\text { (patients/events) }\end{array}$ & $\begin{array}{l}\text { Low expression } \\
\text { (patients/events) }\end{array}$ & $\begin{array}{l}\text { p-value } \\
\text { (BCR) }\end{array}$ \\
\hline AMACR & 3.390 & $72(18)$ & $59 \quad(9)$ & 0.213 \\
\hline AR & 1.113 & $32(8)$ & $99(19)$ & 0.424 \\
\hline EZH2 & 3.883 & $30(10)$ & $101(17)$ & 0.027 \\
\hline FOLH1 & 1.957 & 11 (9) & $120(18)$ & $<0.001$ \\
\hline KLK3 & 0.683 & 31 & 99 (23) & 0.255 \\
\hline PCA3 & 2.452 & $85(21)$ & $46 \quad(6)$ & 0.147 \\
\hline PTEN & -1.300 & $108(17)$ & $23(10)$ & $<0.001$ \\
\hline PDCD6IP & $-1,909$ & $126(24)$ & $5 \quad(3)$ & 0.001 \\
\hline TSG101 & -1.672 & $124(23)$ & 7 (4) & 0.002 \\
\hline UBAP1 & -1.771 & 115 (19) & 16 & $<0.001$ \\
\hline VPS28 & 0.842 & $27 \quad(3)$ & $104(24)$ & 0.912 \\
\hline SNF8 & 1.397 & $10 \quad(0)$ & $121(27)$ & 0.186 \\
\hline VPS25 & -1.651 & $114(21)$ & $17 \quad(6)$ & 0.206 \\
\hline VPS36 & -0.604 & 79 (10) & $52(17)$ & 0.005 \\
\hline IST1 & -2.274 & $121(20)$ & $10 \quad(7)$ & $<0.001$ \\
\hline VPS4A & -2.468 & $126(23)$ & $5 \quad(4)$ & $<0.001$ \\
\hline VTA1 & -1.277 & $120(22)$ & 11 & $<0.001$ \\
\hline RAB5A & -1.506 & $121(22)$ & $10 \quad(5)$ & $<0.001$ \\
\hline RAB27A & 0.607 & $52(6)$ & $79(21)$ & 0.033 \\
\hline RAB27B & -0.301 & $96(15)$ & $35(12)$ & 0.025 \\
\hline RAB35 & -0.802 & $79(12)$ & $52(15)$ & 0.077 \\
\hline TBC1D10A & -0.787 & 61 (9) & $70(18)$ & 0.064 \\
\hline CD9 & -0.9227 & $102(16)$ & $29(11)$ & 0.007 \\
\hline CD63 & 1.814 & 5 (3) & $126(24)$ & 0.014 \\
\hline CD81 & 0.531 & $8 \quad(4)$ & $123(23)$ & 0.014 \\
\hline CHMP4C & 3.266 & 7 (4) & $124(23)$ & 0.004 \\
\hline DCT & -1.809 & $124(24)$ & $7 \quad(3)$ & 0.083 \\
\hline EPCAM & 1.9265 & 68 (18) & $63 \quad(9)$ & 0.111 \\
\hline HSPA4 & -1.489 & $120(22)$ & $11(5)$ & $<0.001$ \\
\hline HSP90AA1 & -1.352 & $124(22)$ & $7 \quad(5)$ & $<0.001$ \\
\hline MMP2 & 1.583 & 7 (3) & $124(24)$ & 0.043 \\
\hline MMP9 & -0.669 & $125(27)$ & $6(0)$ & 0.233 \\
\hline MMP14 & 1.740 & $5(3)$ & $126(24)$ & $<0.001$ \\
\hline STEAP3 & -2.119 & $120(22)$ & 11 (5) & 0.007 \\
\hline
\end{tabular}

${ }^{a}$ Log-rank test revealed candidate genes to be associated with patient outcome after determination of gene expression cut-off values.

were positively correlated in this dataset and also a positive correlation between RAB27B and VPS36 was found (Fig. 4).

Since in silico a downregulation of RAB27A, RAB27B and VPS36 was seen in metastatic $\mathrm{PCa}$, but not in organ confined $\mathrm{PCa}$, a second dataset consisting of patients undergoing transurethral resection of $\mathrm{PCa}$ for palliation, with many of them having metastatic and/or castration-resistant disease and therefore reflecting an advanced disease state, was analyzed.

In this cohort a significant reduction of VPS36 expression in tumor samples $(\mathrm{p}=0.022)$ was found, whilst RAB27A and RAB27B were not reduced in tumor samples, instead showing a slight but not significant increase in expression (Fig. 5A-C). When stratifying the tumor samples into androgen-dependent 

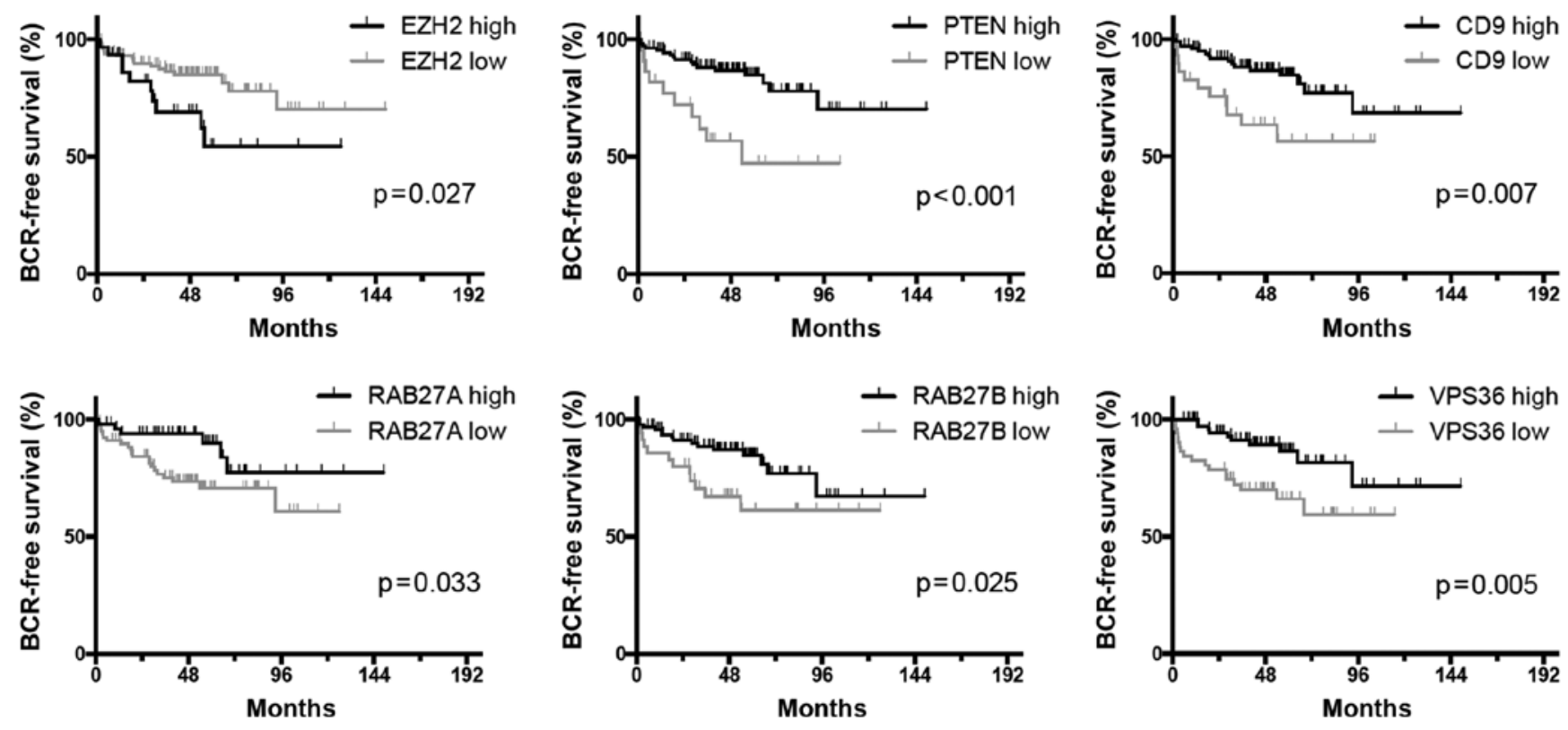

Figure 1. A subset of six genes significantly correlated with BCR-free survival. A higher expression of EZH2 and a lower expression of PTEN, CD9, RAB27A, RAB27B and VPS36 correlated with a shorter BCR-free survival.

A

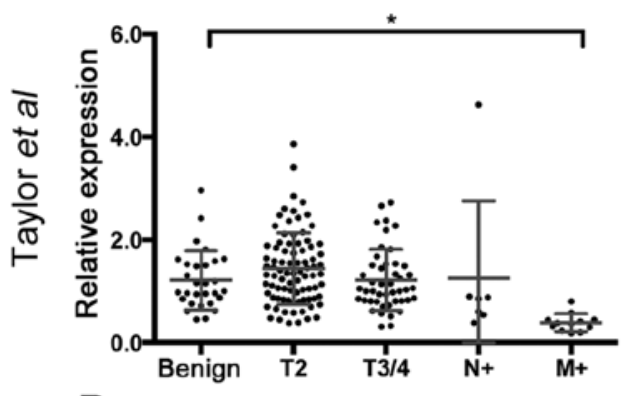

D

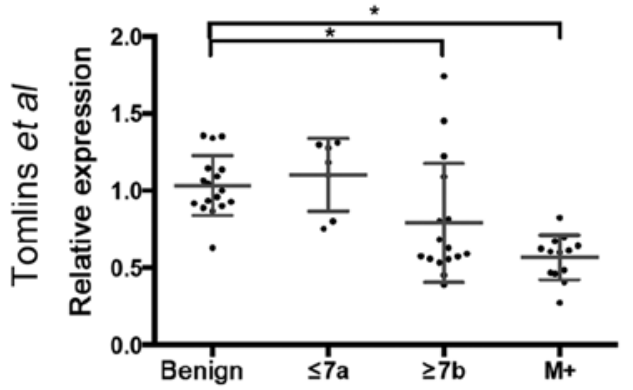

G

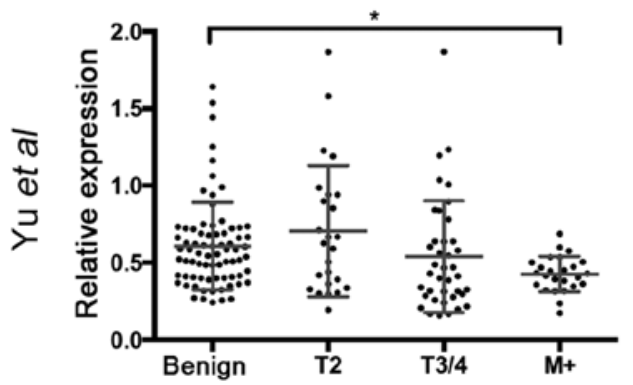

B

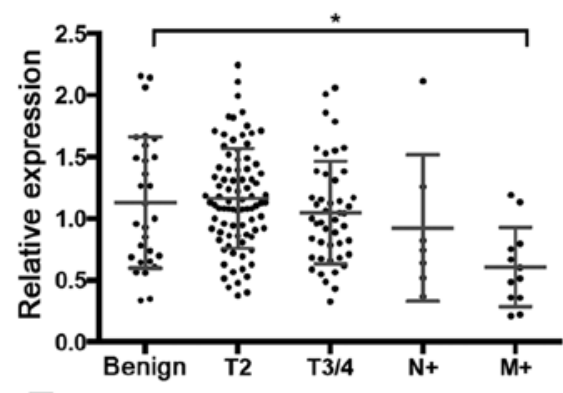

E

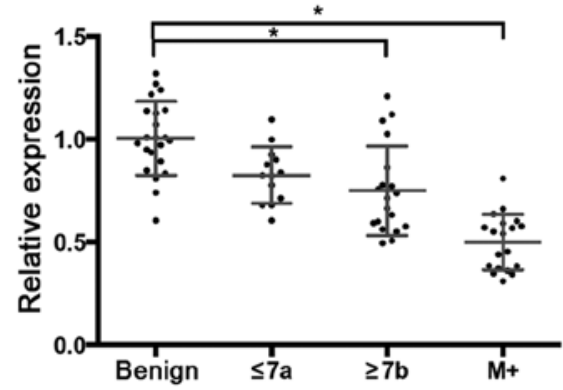

$\mathrm{H}$

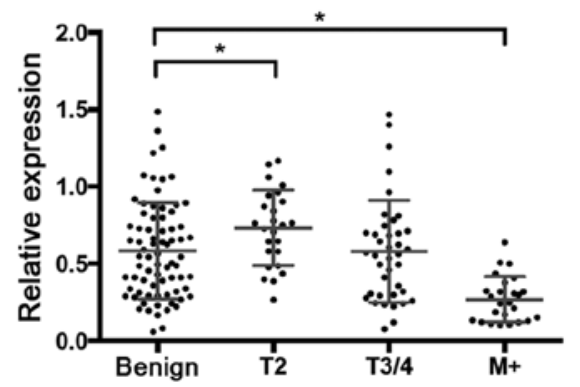

C

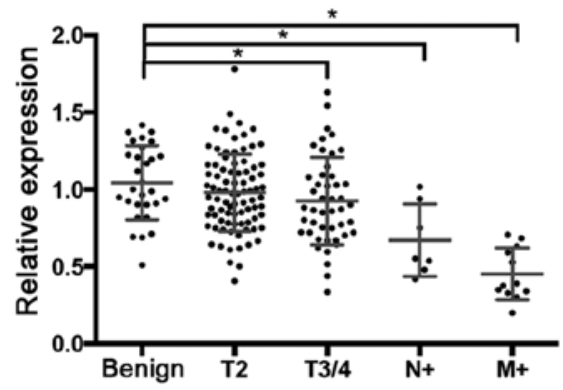

$F$

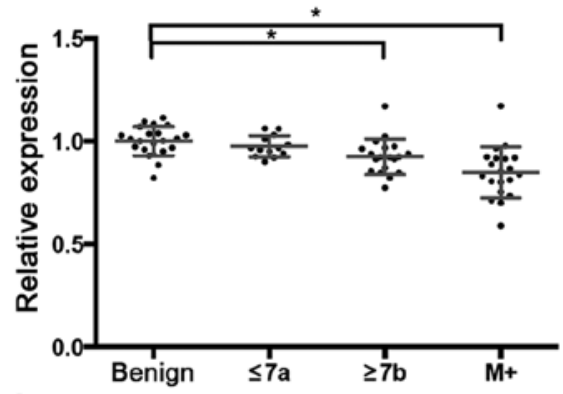

I

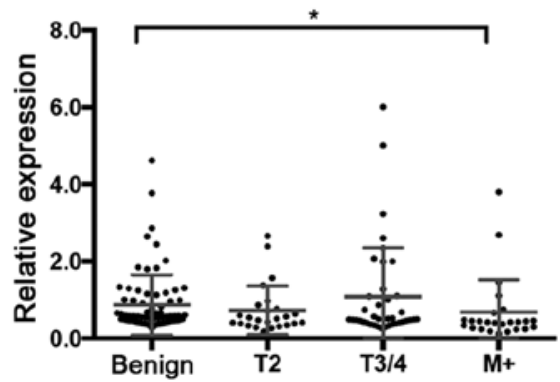

Figure 2. Expression of RAB27A, RAB27B and VPS36 was re-analyzed in three microarray datasets. RAB27A, RAB27B and VPS36 expression was decreased in PCa metastases. For VPS36 a decreased expression was also found in locally advanced PCa and lymph node metastases in the Taylor et al (19) dataset (A-C). RAB27A, RAB27B and VPS36 were also underexpressed in tumors with a Gleason score $\geq 7 \mathrm{~b}$ in the Tomlins et al dataset (21) (D-F). RAB27B was overexpressesed in T2 tumors in the Yu et al dataset (G-I). Expression values are shown as absolute numbers after normalization across the whole dataset. Graphs include mean expression values and SD $\left({ }^{*} \mathrm{p}<0.05\right)$. 


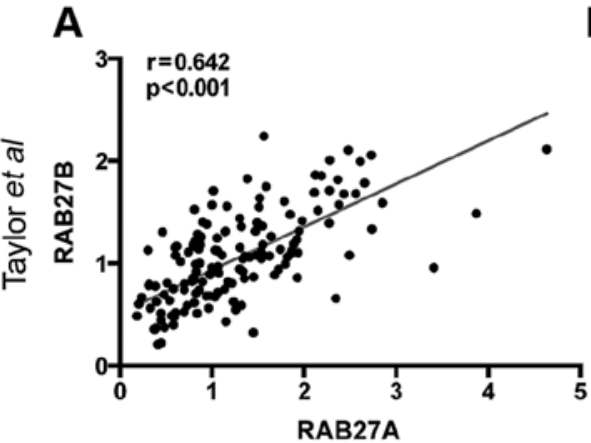

D
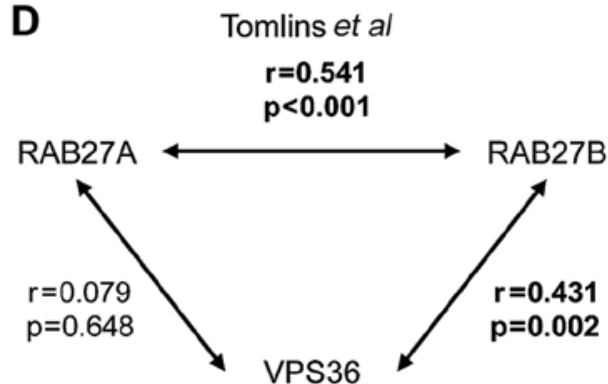

B

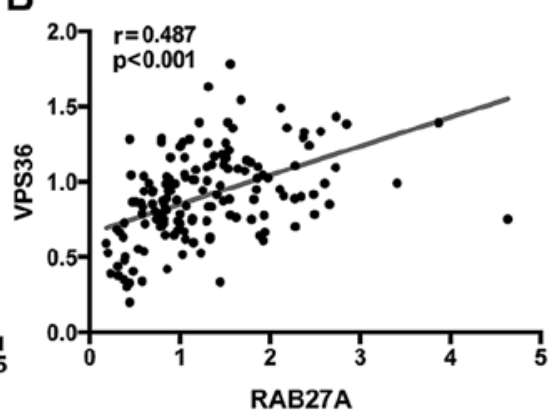

E
C

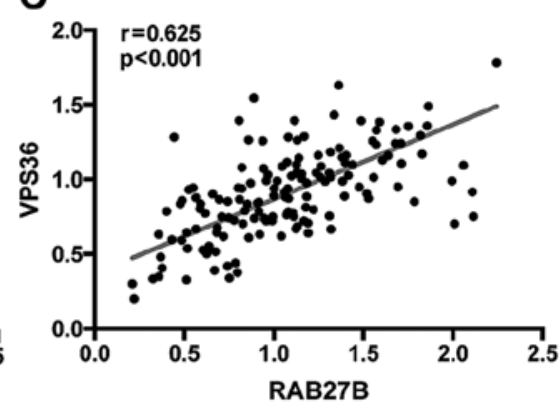

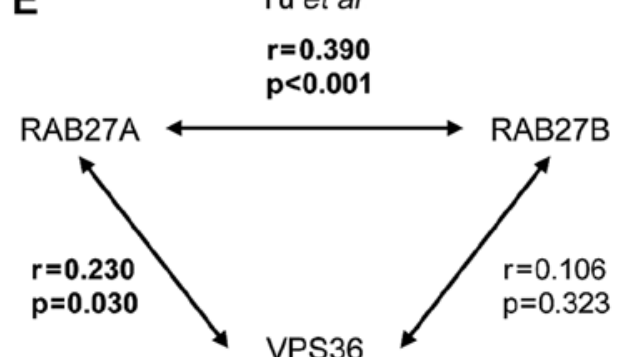

Figure 3. The expression of the single genes in the microarray datasets was correlated among each other. Spearman correlation revealed positive correlation between the expression of RAB27A, RAB27B and VPS36 in the Taylor et al dataset (19) (A-C). This could partly be validated in the Tomlins et al (21) (D) and the Yu et al (22) (E) datasets. The correlation between RAB27A and RAB27B was the strongest.

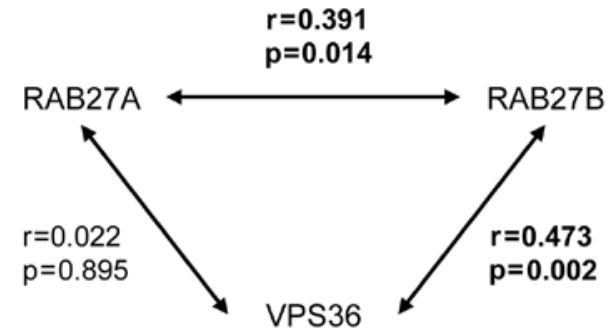

Figure 4. Re-testing on a commercially available cDNA array showed a positive correlation of RAB27B both with RAB27A and VPS36.

(AD) and castration-resistant (CR) tumors according to the clinical data, VPS36, but not RAB27A and RAB27B, was lower expressed in $\mathrm{CR}$ tumors, compared to both controls $(p=0.002)$ and AD tumors ( $p=0.026)$ (Fig. 5E-G).

Furthermore, the expression of AR, typically overexpressed in CR tumors as a sign of aberrant androgen signaling, was analyzed. As expected a strong overexpression of AR in CR tumors compared to controls $(\mathrm{p}<0.001)$ and to AD tumors $(\mathrm{p}<0.001)$ was seen (Fig. 5D and H).

The expression of the three candidate genes positively correlated with each other (Fig. 5I). The expression of VPS36 and RAB27A did not show a significant correlation with AR (Fig. 5J), whilst for RAB27B a positive correlation with AR was seen (Fig. $5 \mathrm{~K}$ ).

Knockdown experiments confirm interdependency of candidate genes. To further elucidate the unknown role of RAB27A, RAB27B and VPS36 in PCa, siRNA-mediated knockdown experiments were performed in the castration-resistant PC3 cell line. Whilst knockdown of RAB27A and RAB27B resulted in no significant changes in the expression of the other genes in PC3 cells, knockdown of VPS36 resulted in a significant increase in the expression of RAB27A $(p=0.001)$ and $\operatorname{RAB} 27 \mathrm{~B}(\mathrm{p}=0.046)$, indicating potential crosstalk (Fig. 6A-C). Interestingly, in MDA-MB-231 breast cancer cells the same dependency with an elevated expression of RAB27A $(\mathrm{p}=0.003)$ and RAB27B $(\mathrm{p}=0.019)$ upon knockdown of VPS36 was seen (Fig. 6D-F).

Knockdown of RAB27B and VPS36 reduces colony formation and increases extracellular particle release. Knockdown of none of the candidates significantly reduced the growth of PC3 cells, measured with MTT assay under standard dense 2D cell culture conditions (Fig. 7A). Also under standard conditions, the migration of PC3 cells, determined by the scratch assay, was not significantly altered upon knockdown of the candidate genes (Fig. 7C).

Unlike in the MTT assay, when transfected PC3 cells were seeded at low density for long-term cultivation, a strong reduction of colony formation upon knockdown of RAB27B $(\mathrm{p}<0.001)$ and VPS36 $(\mathrm{p}<0.001)$, potentially indicating an impairment of paracrine cell-to-cell signaling, was seen (Fig. 7B).

Following this approach, the influence of the candidate genes on the production of extracellular particles not pelleting at $12,000 \mathrm{~g}$ centrifugation, being a surrogate for small extracellular vesicles, was investigated. As control PC3 cells were treated with GW4869, which is a known blocker of the release of exosomes. GW4869 treatment did not significant increase cellular growth, but reduced the number of released particles by $37.1 \%(\mathrm{p}<0.001)$, indicating that the experimental setup could monitor modulations in extracellular vesicle release (Fig. 8A and B). Interestingly there was a significant increase in particle release in PC3 cells upon knockdown of RAB27B 

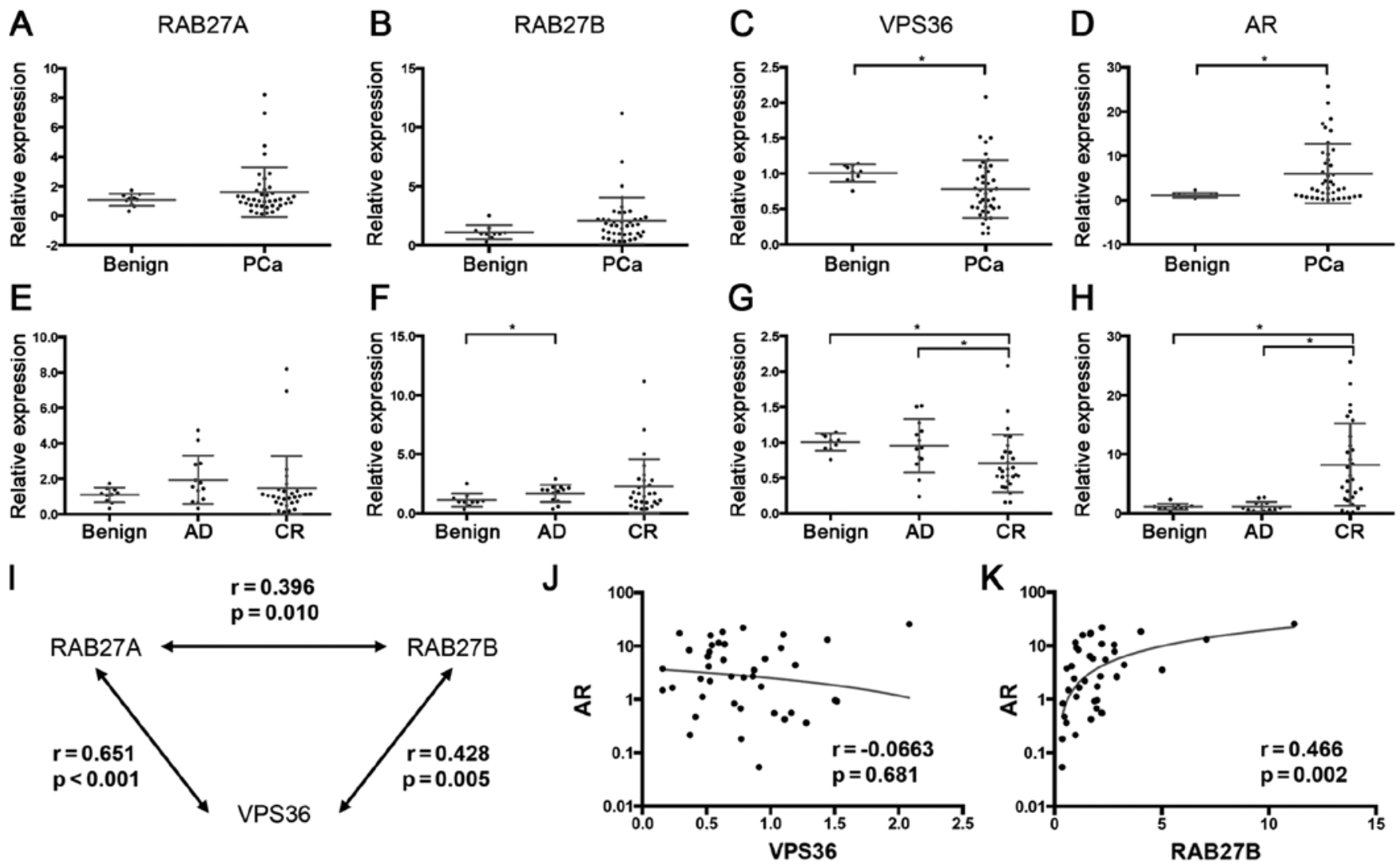

Figure 5. In a cohort of patients from our own institution treated with transurethral resection for palliation of symptomatic PCa, expression of RAB27A and RAB27B was not deregulated (A and B), but VPS36 (C) was decreased and AR increased in PCa samples (D). By stratifying for castration resistance status, no alteration for RAB27A (E) and an increase of RAB27B in AD tumors were seen (F). Interestingly the lowest expression of VPS36 was found in CR PCa samples (G). In the same tumors a strong increase in AR expression could be seen (H). Again the candidate gene expression was positively correlated (I). VPS36 showed a slight tendency to an inverse correlation with AR (J), whilst RAB27B expression was positively correlated with AR (K). Graphs include mean expression values and SD $(* \mathrm{p}<0.05)$.

A

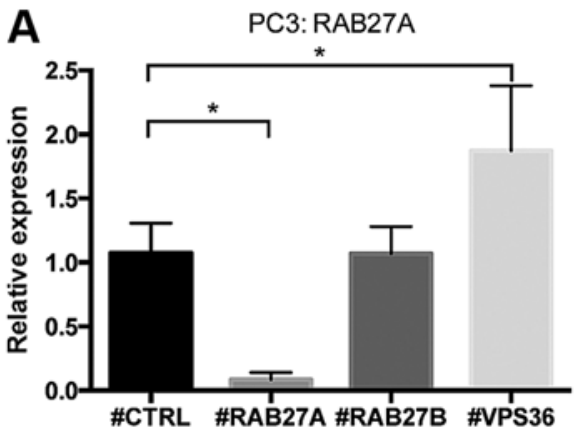

D

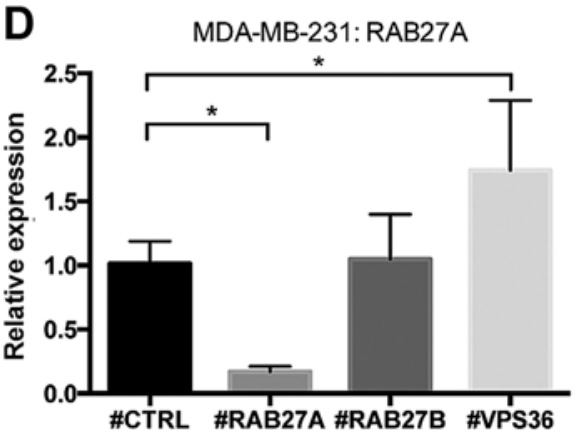

B

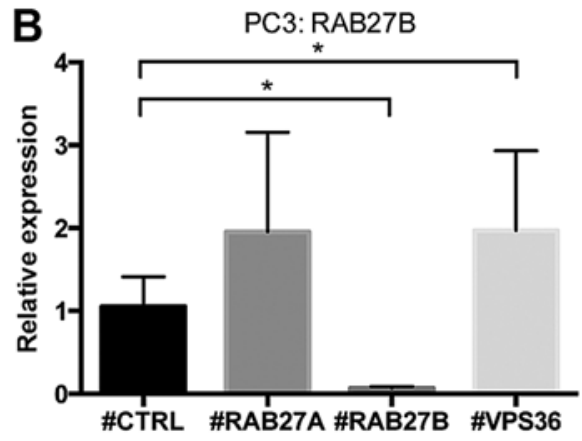

E

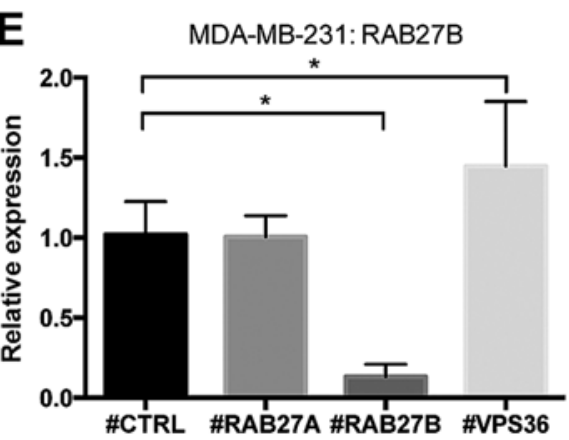

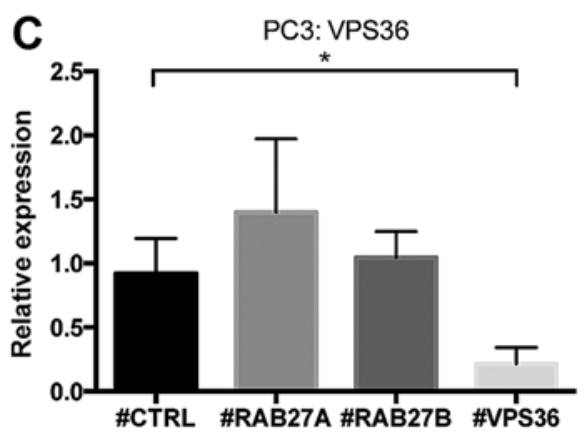

$\mathbf{F}$

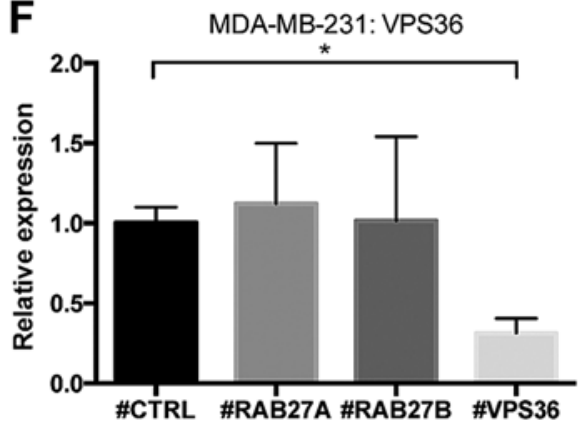

Figure 6. Knockdown of VPS36, RAB27A and RAB27B indicates mutual influence in gene expression both in PC3 cells (A-C) and in MDA MB-231 breast cancer cells (D-F). Expression of both RAB27A and RAB27B increases significantly upon knockdown of VPS36. Expression values are displayed as means with SD ("p<0.05). 

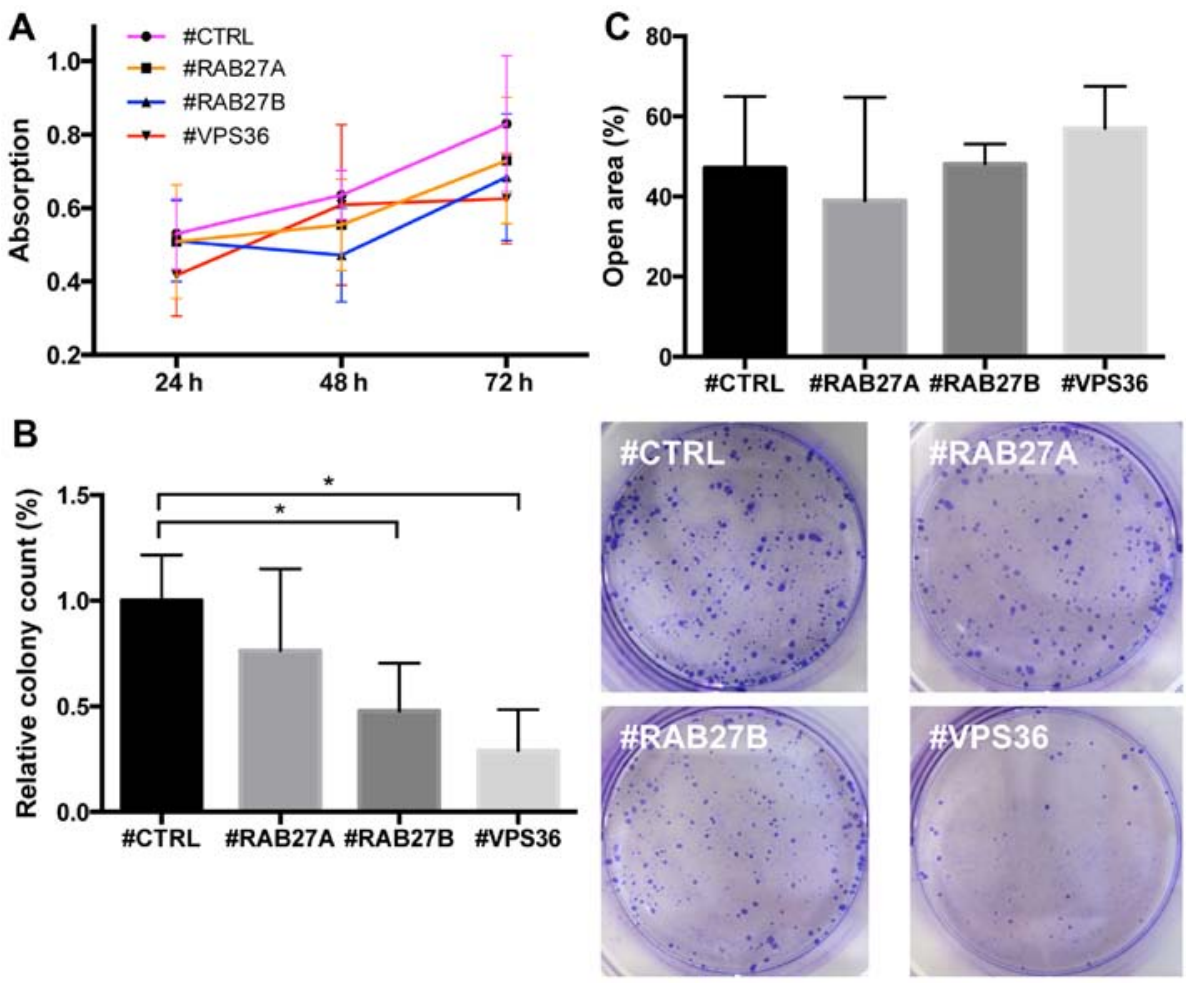

Figure 7. Functional analyses of VPS36, RAB27A and RAB27B were done using siRNA knockdown in PC3 cells. (A) Gene knockdown did not result in a significant reduction of proliferation in PC3 cells under standard conditions, (B) but knockdown of VPS36 and RAB27B strongly affected the cell-cell contact-independent proliferation of PC3 cells. (C) Migration of PC3 cells was not significantly affected upon knockdown. Values are displayed as means with $\mathrm{SD}(\mathrm{p}<0.05)$.
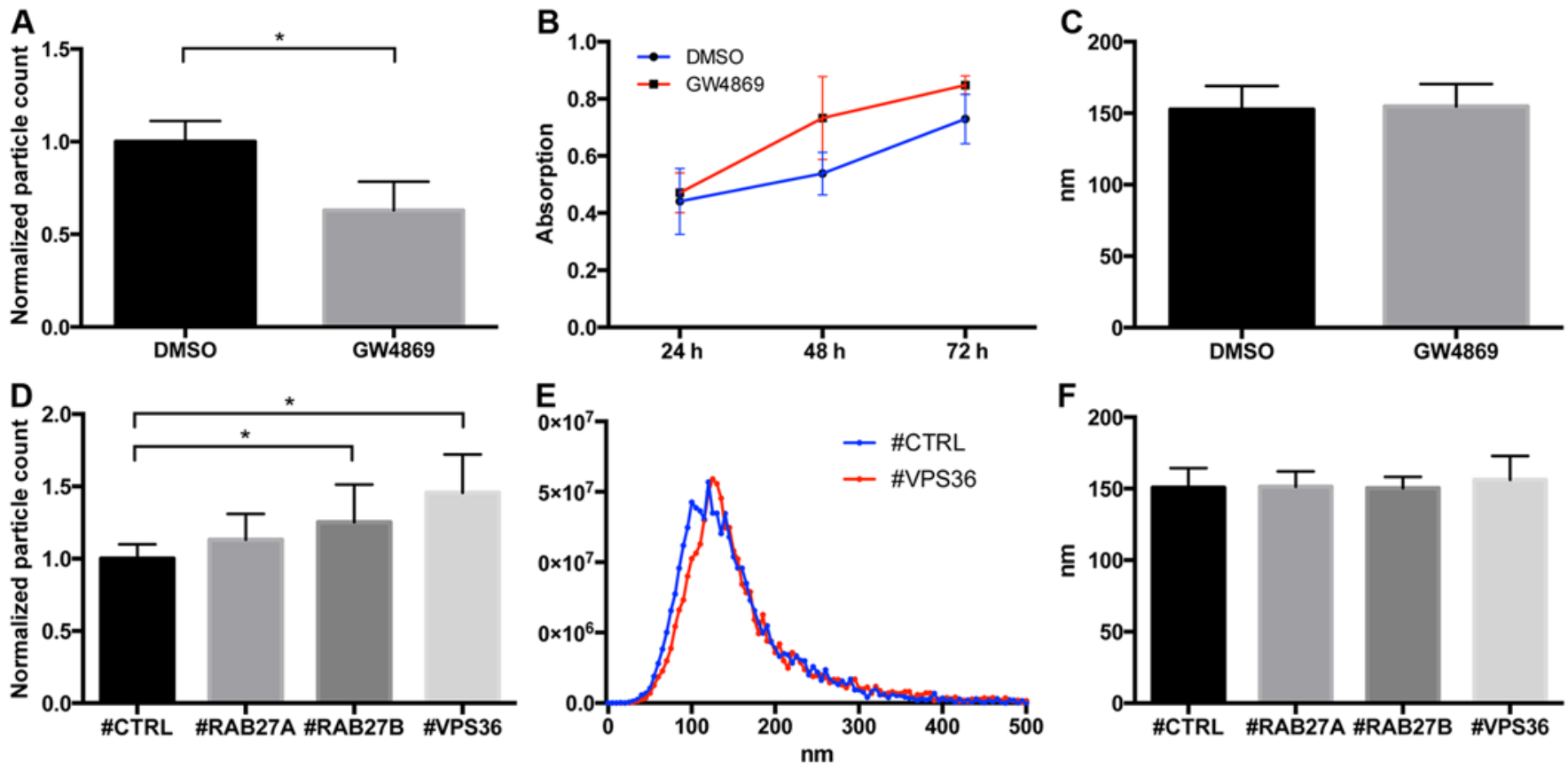

Figure 8. PC3 cells treated with GW4869 released 37\% less extracellular particles (A), whilst no changes in cellular growth (B) and size of the released particles were seen (C). Upon knockdown of RAB27B and VPS36 a significant increase in release of extracellular particles not pelleting at 12,000 g was seen (D). No changes in particle size distribution (E) (exemplarily shown for \#CTRL vs. \#VPS36) and average particle size could be detected (F). Values are displayed as means with SD $($ p $<0.05)$.

$(\mathrm{p}=0.014)$ and VPS36 $(\mathrm{p}<0.001)$, again pointing to an alteration in cell-to-cell signaling dependent on the candidate genes
(Fig. 8D). Both for inhibitor treatment and RNAi no changes in the size of the released particles were seen (Fig. 8C and F). 
Fig. 8E shows the typical size distribution of the particles released from PC3 cells treated with \#CTRL and \#VPS36.

\section{Discussion}

Genes with known function in vesicular trafficking and secretion and genes coding for typical extracellular vesicle marker proteins were analyzed in existing microarray datasets, to investigate their role in $\mathrm{PCa}$, Among these, the expression of VPS36, RAB27A and RAB27B was inversely correlated with $\mathrm{BCR}$-free survival. These three genes were underexpressed in metastatic PCa tissue samples.

$\mathrm{RAB} 27 \mathrm{~A}$ and RAB27B are deemed to be key regulators of exosome secretion, since they mediate the transport of MVBs to the plasma membrane and their fusion with the plasma membrane (13). Several studies have shown their expression to be correlated with exosome release in vitro and in vivo in different cancer entities $(4,28)$. Typically blockage of their expression reduces the number of exosomes secreted (29). Two studies suggest RAB27A to be involved in the secretion of typical PCa markers the PSA and PSAP by modulating PI3K-signaling $(30,31)$. Furthermore, reduction of RAB27A expression results in a reduction of stroma-assisted tumor growth by reducing the number of secreted exosomes from PCa cells (32). It is known that the regulatory effects of RAB27 GTPases are cell-specific, depending on expression and function of potential effector molecules (33). In mast cells they were shown to regulate granule exocytosis, with RAB27B being more of a positive regulator and RAB27A more of a negative regulator of degranulation (34). This underlines that they can both have concordant and discordant function and are also involved in immune-modulatory processes (35).

$\mathrm{RAB} 27 \mathrm{~B}$ is known to be expressed in various epithelial tissues in adults, while RAB27B expression is low in fetal tissue (36). Yet, the expression of RAB27A and RAB27B has only been studied in some cancer entities. In breast cancer an elevated expression of RAB27B is associated with lymph node metastasis and predicts poor prognosis (37). Also in colorectal cancer RAB27B has been identified as potential predictor of metastasis and outcome (38). A higher expression of RAB27B mRNA was observed in cancer tissue and was associated with decreased overall survival. Conversely another study found a lower expression of RAB27A and RAB27B to be correlated with colorectal cancer progression (39). To date nothing is known about the expression of RAB27A and RAB27B in PCa. In this study data from in silico analysis consistently showed the expression of both genes to be lower in PCa metastases. In the Tomlins et al dataset (21) both genes were also underexpressed in localized PCa with a Gleason score of $7 \mathrm{~b}$ and higher. Also a positive correlation between RAB27B and AR was seen. A recent study found the expression of RAB27A to be regulated by AR upon androgen deprivation therapy in $\mathrm{PCa}(40)$, but the underlying mechanisms are yet unknown.

Unlike for RAB27A and RAB27B, the role of VPS36 in cancer has not been investigated at all. As a member of the ESCRT-II complex it is mainly associated with MVB biogenesis, cellular abscission and viral budding (41). Deregulation of JAK/STAT signaling in tissues with modifications in the ESCRT-II complex resulted in facilitated tumorigenesis in Drosophila, indicating crosstalk with known cancer-pathways
(42). VPS36, also known as EAP45, is located on chromosome 13 and transcribes for three different transcript variants. Crystal structure analyses propose it to directly interact with ubiquitinated proteins (43). It showed a negative correlation with advanced tumor stage and worse outcome in silico. This was confirmed by qRT-PCR analysis. Especially in CR PCa VPS36 expression was significantly reduced, whilst AR expression was strongly increased. Yet, no significant correlation between these two genes was seen.

Both in existing microarray datasets and in tumor samples analyzed with qRT-PCR, the expression of the candidate genes was consistently correlated among each other. This might be due to a mechanism simultaneously regulating the candidate gene expression. In vitro a significant increase of RAB27A and RAB27B expression was seen upon knockdown of VPS36 in PC 3 cells, but not vice versa. This suggests an additional directional interdependency of these genes. At least with regard to exosome release VPS36 is located prior in the signaling cascade, making this relationship plausible. Re-testing in the MDA MB-231 breast cancer cell line confirmed these results and suggests this interdependency not to be PCa-specific.

Knockdown of the candidate genes did not result in a significant alteration of growth and migration of PC3 cells under standard culture conditions. The significant reduction of colony formation upon knockdown of RAB27B and VPS36 seems to be controversial to the findings in patient samples. Yet, cellular behavior in this long-term setup is less dependent on the induced changes in the individual cells and direct cellto-cell interaction. Instead it also reflects aspects of paracrine stimulation via secreted molecules and particles like exosomes. Again comparable data from other studies in PCa are lacking. In vivo data from lung cancer mouse models show a reduction of tumor growth only for metastatic, but not for non-metastatic cell lines treated with shRNAs targeting RAB27A (4).

To investigate the impact of candidate gene expression on extracellular vesicle secretion, NTA analyses of the supernatant of treated cells were conducted. In order to facilitate measurement of multiple samples under different treatment conditions, particles in the supernatant of cancer cells not pelleting at $12,000 \mathrm{~g}$ were used as a surrogate for small extracellular vesicles. Using this system, treatment of PC3 cells with the sphingomyelinase inhibitor GW4869, a known blocker of exosome release (44), resulted in a strong reduction of extracellular particles, indicating the applicability of this setup. Unexpectedly, knockdown of RAB27B and VPS36 resulted in a significant increase of extracellular particles remaining in the $\mathrm{PC} 3$ supernatant after centrifugation at 12,000 g. Again, there is not much comparable data in the literature. One study has used a similar experimental setup to monitor vesicle release from MDA MB-231 cells. shRNA-mediated knockout of RAB27A resulted in a significant decrease of secreted vesicles (29). As in this study, no changes in the size of secreted particles were observed. RAB27B and VPS36 were not tested in this study. Ostrowski et al (13) also found no changes in size and morphology of HeLa exosomes upon shRNA mediated knockdown of RAB27A and RAB27B. By analyzing ultracentrifugation pellets they saw a reduction of exosomes upon knockdown, which is controversial to our findings. These different observations might be attributed to the different assay and readout conditions. Also a time-dependent regulation of extracellular particle release upon modulation of 
RAB27A and RAB27B expression can be debated. Furthermore, the used cell lines represent different cancer entities with a potentially different regulation of RAB27A and RAB27B expression and function. Also the different cell lines originate from different microenvironmental conditions. In this context it has been shown that extracellular vesicles of malignant cells have an ambivalent role both in immune-evasion $(45,46)$ and the activation of the immune system against cancer cells (47), adding a further potential regulatory element on extracellular vesicle biogenesis and secretion.

Our study is limited by the heterogeneous assay platforms used for microarray experiments. Furthermore, sample handling and data post-processing offer potential source of bias. The cohorts analyzed by qRT-PCR were heterogeneous with regard to tumor stage and, mainly for the patients treated with transurethral resection, also for iatrogenous factors as pretreatment and castration-resistance. Also the sample material itself, being FFPE tissue, is not optimal for downstream analyses due to a strong degradation of nucleic acids. Yet studies relying on antibody-based protein analyses, being an alternative strategy to analyze candidate expression, also have specific limitations such as degradation of epitopes, unspecific antibody binding and a more difficult quantification.

In conclusion, several genes with known function in vesicular trafficking and secretion are deregulated in $\mathrm{PCa}$. Of these, RAB27A, RAB27B and VPS36 are consistently underexpressed in advanced $\mathrm{PCa}$ and predict worse outcome. For VPS36 underexpression could also be shown in primary tumors undergoing local palliation. Subgroup analysis indicates a stronger decrease in CR tumors, whilst no correlation was found with the expression the AR.

In the analyzed datasets the expression of RAB27A, RAB27B and VPS36 showed a strong positive correlation among each other, pointing to a common regulatory mechanism. Additionally in vitro manipulation of the gene expression indicates RAB27A and RAB27B to be dependent of VPS36. An increase of extracellular particles and a reduction of colony formation upon knockdown of RAB27B and VPS36 indicate an involvement in paracrine cell-cell communication.

Further analyses in larger cohorts are needed to validate the repressed expression of VPS36, RAB27A and RAB27B in advanced and metastatic PCa. Additionally, studies dissecting their specific regulation and function should help to elucidate their role in vesicular trafficking and secretion and paracrine signaling in $\mathrm{PCa}$.

\section{Acknowledgements}

This study was supported by the Foundation on Cancer and Scarlet Research of the University of Heidelberg. T.S.W. was supported by a Ferdinand Eisenberger scholarship of the German Society of Urology.

\section{References}

1. Jemal A, Bray F, Center MM, Ferlay J, Ward E and Forman D: Global cancer statistics. CA Cancer J Clin 61: 69-90, 2011.

2. Vlassov AV, Magdaleno S, Setterquist R and Conrad R: Exosomes: Current knowledge of their composition, biological functions, and diagnostic and therapeutic potentials. Biochim Biophys Acta 1820: 940-948, 2012.
3. Junker K, Heinzelmann J, Beckham C, Ochiya T and Jenster G: Extracellular vesicles and their role in urologic malignancies. Eur Urol 70: 323-331, 2016.

4. Bobrie A, Krumeich S, Reyal F, Recchi C, Moita LF, Seabra MC, Ostrowski M and Théry C: Rab27a supports exosome-dependent and -independent mechanisms that modify the tumor microenvironment and can promote tumor progression. Cancer Res 72: 4920-4930, 2012.

5. Beckham CJ, Olsen J, Yin P-N, Wu CH, Ting HJ, Hagen FK, Scosyrev E, Messing EM and Lee YF: Bladder cancer exosomes contain EDIL-3/Del1 and facilitate cancer progression. J Urol 192: 583-592, 2014.

6. Alderton GK: Metastasis. Exosomes drive premetastatic niche formation. Nat Rev Cancer 12: 447, 2012.

7. Peinado H, Alečković M, Lavotshkin S, Matei I, Costa-Silva B, Moreno-Bueno G, Hergueta-Redondo M, Williams C, GarcíaSantos G, Ghajar C, et al: Melanoma exosomes educate bone marrow progenitor cells toward a pro-metastatic phenotype through MET. Nat Med 18: 883-891, 2012.

8. Webber MM, Trakul N, Thraves PS, Bello-DeOcampo D, Chu WW, Storto PD, Huard TK, Rhim JS and Williams DE: A human prostatic stromal myofibroblast cell line WPMY-1: A model for stromal-epithelial interactions in prostatic neoplasia. Carcinogenesis 20: 1185-1192, 1999.

9. Webber J, Steadman R, Mason MD, Tabi Z and Clayton A: Cancer exosomes trigger fibroblast to myofibroblast differentiation. Cancer Res 70: 9621-9630, 2010.

10. Colombo M, Moita C, van Niel G, Kowal J, Vigneron J, Benaroch P, Manel N, Moita LF, Théry C and Raposo G: Analysis of ESCRT functions in exosome biogenesis, composition and secretion highlights the heterogeneity of extracellular vesicles. J Cell Sci 126: 5553-5565, 2013.

11. Adell MA and Teis D: Assembly and disassembly of the ESCRT-III membrane scission complex. FEBS Lett 585: 3191-3196, 2011.

12. Brinton LT, Sloane HS, Kester M and Kelly KA: Formation and role of exosomes in cancer. Cell Mol Life Sci 72: 659-671, 2015.

13. Ostrowski M, Carmo NB, Krumeich S, Fanget I, Raposo G, Savina A, Moita CF, Schauer K, Hume AN, Freitas RP, et al: Rab27a and Rab27b control different steps of the exosome secretion pathway. Nat Cell Biol 12: 19-30, 2010.

14. Théry C, Amigorena S, Raposo G and Clayton A: Isolation and characterization of exosomes from cell culture supernatants and biological fluids. Curr Protoc Cell Biol Chapter 3: Unit 3.22, 2006.

15. Théry C, Zitvogel L and Amigorena S: Exosomes: Composition, biogenesis and function. Nat Rev Immunol 2: 569-579, 2002.

16. Villarroya-Beltri C, Gutiérrez-Vázquez C, Sánchez-Cabo F, Pérez-Hernández D, Vázquez J, Martin-Cofreces $\mathrm{N}$, Martinez-Herrera DJ, Pascual-Montano A, Mittelbrunn M and Sánchez-Madrid F: Sumoylated hnRNPA2B1 controls the sorting of miRNAs into exosomes through binding to specific motifs. Nat Commun 4: 2980, 2013.

17. Koppers-Lalic D, Hackenberg M, Bijnsdorp IV, van Eijndhoven MA, Sadek P, Sie D, Zini N, Middeldorp JM, Ylstra B, de Menezes RX, et al: Nontemplated nucleotide additions distinguish the small RNA composition in cells from exosomes. Cell Rep 8: 1649-1658, 2014

18. van der Pol E, Böing AN, Harrison P, Sturk A and Nieuwland R: Classification, functions, and clinical relevance of extracellular vesicles. Pharmacol Rev 64: 676-705, 2012.

19. Taylor BS, Schultz N, Hieronymus H, Gopalan A, Xiao Y, Carver BS, Arora VK, Kaushik P, Cerami E, Reva B, et al: Integrative genomic profiling of human prostate cancer. Cancer Cell 18: 11-22, 2010.

20. Cerami E, Gao J, Dogrusoz U, Gross BE, Sumer SO, Aksoy BA, Jacobsen A, Byrne CJ, Heuer ML, Larsson E, et al: The cBio cancer genomics portal: An open platform for exploring multidimensional cancer genomics data. Cancer Discov 2: 401-404, 2012.

21. Tomlins SA, Mehra R, Rhodes DR, Cao X, Wang L, Dhanasekaran SM, Kalyana-Sundaram S, Wei JT, Rubin MA, Pienta KJ, et al: Integrative molecular concept modeling of prostate cancer progression. Nat Genet 39: 41-51, 2007.

22. Yu YP, Landsittel D, Jing L, Nelson J, Ren B, Liu L, McDonald C, Thomas R, Dhir R, Finkelstein S, et al: Gene expression alterations in prostate cancer predicting tumor aggression and preceding development of malignancy. J Clin Oncol 22: 2790-2799, 2004. 
23. Specht E, Kaemmerer D, Sänger J, Wirtz RM, Schulz S and Lupp A: Comparison of immunoreactive score, HER $2 /$ neu score and $\mathrm{H}$ score for the immunohistochemical evaluation of somatostatin receptors in bronchopulmonary neuroendocrine neoplasms. Histopathology 67: 368-377, 2015.

24. Kaemmerer D, Reimann C, Specht E, Wirtz RM, Sayeg M, Baum RP, Schulz S and Lupp A: Differential expression and prognostic value of the chemokine receptor CXCR4 in bronchopulmonary neuroendocrine neoplasms. Oncotarget 6: 3346-3358, 2015.

25. Untergasser A, Cutcutache I, Koressaar T, Ye J, Faircloth BC, Remm M and Rozen SG: Primer3 - new capabilities and interfaces. Nucleic Acids Res 40: e115, 2012.

26. Livak KJ and Schmittgen TD: Analysis of relative gene expression data using real-time quantitative PCR and the $2(-\Delta \Delta \mathrm{C}(\mathrm{T}))$ method. Methods 25: 402-408, 2001.

27. Ashby WJ and Zijlstra A: Established and novel methods of interrogating two-dimensional cell migration. Integr Biol 4: $1338-1350,2012$

28. Li W, Hu Y, Jiang T, Han Y, Han G, Chen J and Li X: Rab27A regulates exosome secretion from lung adenocarcinoma cells A549: Involvement of EPI64. APMIS 122: 1080-1087, 2014.

29. Zheng Y, Campbell EC, Lucocq J, Riches A and Powis SJ: Monitoring the Rab27 associated exosome pathway using nanoparticle tracking analysis. Exp Cell Res 319: 1706-1713, 2013.

30. Johnson JL, Ellis BA, Noack D, Seabra MC and Catz SD: The Rab27a-binding protein, JFC1, regulates androgen-dependent secretion of prostate-specific antigen and prostatic-specific acid phosphatase. Biochem J 391: 699-710, 2005.

31. Catz SD: Characterization of Rab27a and JFC1 as constituents of the secretory machinery of prostate-specific antigen in prostate carcinoma cells. Methods Enzymol 438: 25-40, 2008

32. Webber JP, Spary LK, Sanders AJ, Chowdhury R, Jiang WG Steadman R, Wymant J, Jones AT, Kynaston H, Mason MD, et al: Differentiation of tumour-promoting stromal myofibroblasts by cancer exosomes. Oncogene 34: 290-302, 2015.

33. Catz SD: Regulation of vesicular trafficking and leukocyte function by Rab27 GTPases and their effectors. J Leukoc Biol 94 613-622, 2013

34. Singh RK, Mizuno K, Wasmeier C, Wavre-Shapton ST, Recchi C, Catz SD, Futter C, Tolmachova T, Hume AN and Seabra MC: Distinct and opposing roles for Rab27a/Mlph/MyoVa and Rab27b/Munc13-4 in mast cell secretion. FEBS J 280: 892-903, 2013.

35. Elstak ED, Neeft M, Nehme NT, Voortman J, Cheung M, Goodarzifard M, Gerritsen HC, van Bergen En Henegouwen PM, Callebaut I, de Saint Basile G, et al: The munc13-4-rab27 complex is specifically required for tethering secretory lysosomes at the plasma membrane. Blood 118: 1570-1578, 2011.
36. Hendrix A, Lambein K, Westbroek W, Seabra MC, Cocquyt V, Pauwels P, Bracke M, Gespach C and De Wever O: An immunohistochemical analysis of Rab27B distribution in fetal and adult tissue. Int J Dev Biol 56: 363-368, 2012.

37. Zhang J-X, Huang X-X, Cai M-B, Tong ZT, Chen JW, Qian D, Liao YJ, Deng HX, Liao DZ, Huang MY, et al: Overexpression of the secretory small GTPase Rab27B in human breast cancer correlates closely with lymph node metastasis and predicts poor prognosis. J Transl Med 10: 242, 2012.

38. Bao J, Ni Y, Qin H, Xu L, Ge Z, Zhan F, Zhu H, Zhao J, Zhou X, Tang X, et al: Rab27b is a potential predictor for metastasis and prognosis in colorectal cancer. Gastroenterol Res Pract 2014: 913106, 2014.

39. Dong W, Cui J, Yang J, Li W, Wang S, Wang X, Li X, Lu Y and Xiao W: Decreased expression of Rab27A and Rab27B correlates with metastasis and poor prognosis in colorectal cancer. Discov Med 20: 357-367, 2015.

40. Shaw GL, Whitaker H, Corcoran M, Dunning MJ, Luxton H, Kay J, Massie CE, Miller JL, Lamb AD, Ross-Adams H, et al: The early effects of rapid androgen deprivation on human prostate cancer. Eur Urol 70: 214-218, 2016.

41. Schuh AL and Audhya A: The ESCRT machinery: From the plasma membrane to endosomes and back again. Crit Rev Biochem Mol Biol 49: 242-261, 2014.

42. Woodfield SE, Graves HK, Hernandez JA and Bergmann A: De-regulation of JNK and JAK/STAT signaling in ESCRT-II mutant tissues cooperatively contributes to neoplastic tumorigenesis. PLoS One 8: e56021, 2013.

43. Alam SL, Langelier C, Whitby FG, Koirala S, Robinson H, Hill CP and Sundquist WI: Structural basis for ubiquitin recognition by the human ESCRT-II EAP45 GLUE domain. Nat Struct Mol Biol 13: 1029-1030, 2006.

44. Chairoungdua A, Smith DL, Pochard P, Hull M and Caplan MJ: Exosome release of $\beta$-catenin: A novel mechanism that antagonizes Wnt signaling. J Cell Biol 190: 1079-1091, 2010.

45. Liu Y, Gu Y and Cao X: The exosomes in tumor immunity. OncoImmunology 4: e1027472, 2015.

46. Lundholm M, Schröder M, Nagaeva O, Baranov V, Widmark A Mincheva-Nilsson L and Wikström P: Prostate tumor-derived exosomes down-regulate NKG2D expression on natural killer cells and $\mathrm{CD}^{+} \mathrm{T}$ cells: Mechanism of immune evasion. PLoS One 9: e108925, 2014.

47. Li W, Mu D, Tian F, Hu Y, Jiang T, Han Y, Chen J, Han G and Li X: Exosomes derived from Rab27a-overexpressing tumor cells elicit efficient induction of antitumor immunity. Mol Med Rep 8: 1876-1882, 2013. 